\title{
Aspectos cognitivos da literatura
}

\author{
Cognitive Aspects of Literature
}

Axel Gellhaus*

\begin{abstract}
The article presentes theoretical questions to be further developed in future research about the cognitive aspects of literature. The author considers the literary text to have a specific cognitive function that differs from the conceptual and abstract thinking and offers to the readership models for human actions and for the perception of the world.
\end{abstract}

Key-words: Literature; Cognition; Theory of Literature

Resumo: O artigo apresenta uma reflexão teórica, a ser desenvolvida em futuras pesquisas, sobre os aspectos cognitivos da literatura. Considera-se que o texto literário possui uma função cognitiva específica, diversa do pensamento conceitual e abstrato, e oferece ao leitor modelos de ação humana e de percepção do mundo.

Palavras-Chave: Literatura; Cognição; Teoria literária

\section{Introdução da tradutora}

Apresentamos o texto da palestra de Axel Gellhaus sobre os Aspectos Cognitivos da Literatura. A palestra foi ministrada no âmbito do encontro Neuroästhetik. Perspektiven auf ein interdisziplinäres Forschungsgebiet [Neuroestética. Perspectivas para um campo de pesquisas interdisciplinar], realizado em janeiro de 2010, na RWTH-Aachen, em Aachen, na Alemanha. O tema do encontro pode surpreender o leitor brasileiro ainda não familiarizado com os diálogos interdisciplinares entre as Ciências Humanas e as Neurociências. Em que pesem alguns modismos, reduções e exageros com relação à potencialidade de explicações que podem ser

\footnotetext{
* Professor titular do Germanistisches Institut da RWTH-Aachen. Email: a.gellhaus@germlit.rwthaachen.de

Agradecemos ao autor a cessão dos direitos para esta tradução. O texto em alemão foi publicado no livro: Kognitive Aspekte der Literatur. In: HerRmANn, Karin (Hg.). Neuroästhetik. Perspektiven auf ein interdisziplinäres Forschungsgebiet. Beiträge des Impuls-Workshops am 15. und 16. Januar 2010 in Aachen. Kassel 2011 (= Studien des Aachener Kompetenzzentrums für Wissenschaftsgeschichte 10). S. 77-86.
} 
Gellhaus, A. - Aspectos cognitivos da literatura

dadas pelas neurociências aos mais diversos fenômenos, há um diálogo sério e profícuo entre os dois âmbitos do saber, sobretudo nos EUA, na Inglaterra e na Alemanha.

O texto de Gellhaus oferece pontos de reflexão para a elaboração de uma possível teoria sobre as relações entre a literatura, as artes e a cognição. Suas reflexões partem, sobretudo, de seu trabalho como editor das edições críticas de autores como Schiller, Paul Celan e Ernst Meister, e de suas pesquisas sobre os processos de gênese de textos literários, na área de estudos chamada, na Alemanha, de Textgenetik [Genética do texto].

Axel Gellhaus nasceu em Düsseldorf, em 1950. Estudou Germanística, Filosofia, Literatura Comparada, História da Arte e Pedagogia na Universidade de Bonn; na mesma Universidade foi colaborador da Schiller Nationalausgabe, sob a coordenação de Norbert Oellers, trabalhando na edição do volume 32 (Schillers Briefe 1803-1805), e obteve o título de doutor em Germanística, Filosofia e Pedagogia. Ainda em Bonn, foi colaborador de Beda Allemann na edição históricocrítica das obras de Paul Celan, a chamada Bonner Celan-Ausgabe, cuja responsabilidade assumiu, com Rolf Bücher, em 1993. Desde 1997, é professor titular do Germanistisches Institut [Instituto de Germanística] da RWTH-Aachen; também é pesquisador do projeto Brain/Concept/Writing.

Esperamos, com esta tradução, fomentar a discussão sobre as relações entre literatura e cognição no Brasil e oferecer subsídios para futuras pesquisas sobre o tema.

Juliana P. Perez

Universidade de São Paulo 


\section{Aspectos cognitivos da literatura}

Axel Gellhaus

A questão da função cognitiva da literatura não é um tema amplamente discutido nem sequer nos Estudos Literários ${ }^{\mathrm{i}}$, tanto menos é de se supor que nas Ciências da Cognição já estabelecidas haja consciência dos aspectos cognitivos dos textos literários. São admitidas a função da literatura como meio de entretenimento e como instrumento de uma didática - desde a Antiguidade - , a função como meio de comunicação social, há algumas décadas e, mais recentemente, também como meio de articulação do emocional (FU Berlin: Languages of Emotion). ${ }^{\mathrm{ii}} \mathrm{O}$ conceito pós-estruturalista ${ }^{1}$ de Episteme (épistémè), que às vezes também é aplicado à literatura, não contribuiu para uma formulação precisa de suas funções cognitivas. Na verdade, o aspecto de sua relevância para o conhecimento [Erkenntnis] foi tratado pela Estética filosófica por mais de dois séculos, mas o patamar que a arte como órgão de conhecimento atingiu no início do século XIX, na filosofia idealista de Schelling, nunca mais foi alcançado nem mesmo na Estética. Antes se vê confirmada a famosa e famigerada frase de Hegel sobre o "fim da arte", na medida em que raramente é concedido às artes um papel de liderança intelectual e, na arquitetura interna da consciência científica de hoje, a arte se encontra novamente sobretudo no quarto dos brinquedos, limitada às grades mais ou menos vazadas da sua - assim chamada desde Kant - "autonomia". Aqui ela tem liberdade para se "realizar", em geral, sem precisar temer um juízo moral ou científico. A arte joga e, normalmente, seus protagonistas não precisam temer nenhuma consequência séria, enquanto eles não se encontrarem em um sistema social totalitário. Então, sem dúvida, mostra-se ex negativo um potencial para o qual as culturas midiáticas ocidentais

\footnotetext{
${ }^{\mathrm{i}} \mathrm{O}$ termo Literaturwissenschat, ao pé da letra, Ciência da Literatura, foi traduzido neste texto por estudos literários, por ser esta a expressão mais utilizada atualmente no meio acadêmico brasileiro. [N. d. T.]

ii $\mathrm{O}$ autor se refere ao Cluster Languages of Emotion, sediado na Freie Universität de Berlim. Cf. http://www.languages-of-emotion.de/ (acesso 20/07/2012). N. d. T.

${ }^{1}$ Como conceito em sentido estrito 'Episteme' não é nem mesmo definida pelo seu inventor Foucault.
} 
Gellhaus, A. - Aspectos cognitivos da literatura

parecem ter perdido toda a sensibilidade. Além disso, representantes da teoria do sistema diagnosticaram que as formas da literatura, por exemplo, estão inteiramente cristalizadas há muito tempo e a continuação são apenas variações e diferenciações do já conhecido. As ciências tradicionais que se ocupam com questões da arte rapidamente deslizam, em seu prestígio social e na consciência da scientific community, para as proximidades de uma pedagogia de museu: como história dos problemas, história das mentalidades ou das culturas, elas se vêem no papel de um paleontólogo ou arqueólogo de um saber petrificado que se tornou obsoleto ou inútil como saber positivo sobre o mundo e cujo valor de entretenimento e compreensibilidade diminuem conforme o grau de sua distância temporal.

Entretanto, uma aproximação entre as ciências da cognição e as artes acontece a despeito das tendências uniformizantes da grande mídia - de duas formas: nos últimos anos, na trilha do narrative turn - não apenas - dos estudos literários, os aspectos cognitivos ganham cada vez mais espaço na análise de procedimentos literários. ${ }^{2}$ Por outro lado, nesse meio tempo, a pergunta sobre quão literária é a nossa consciência não apenas na composição da literatura, mas também na (re)construção de nexos de experiência também ocupa a pesquisa cerebral séria. ${ }^{3}$ Em que medida a consciência recorre a modelos literários sem saber e sem refletir? A psicologia e as ciências da comunicação trabalham há muito tempo com o conceito de esquema; mas até agora o papel das artes na prefiguração de tais esquemas como abstração de experiência mal começou a ser examinado - nem mesmo pelos Estudos das Artes, por exemplo, a partir do material concreto da gênese das obras. ${ }^{4}$

Que no decorrer de sua recepção textos originalmente literários - isto é, articulações individuais de experiências no mais alto grau -, tenham se tornado exemplo, esquema e, em alguns casos, até cliché pode ser facilmente mostrado. Mas a

\footnotetext{
${ }^{2}$ A partir dos estudos literários anglo-americanos expande-se aos poucos a influência de uma ciência da literatura e das artes na linha cognitiva. Cf. por exemplo STOCKWELL (2002); ELSNER-FRICK (2004), HUBER-WINKO (2009).

${ }^{3}$ Cf. TURNER (1997), prefácio: "Story is a basic principle of mind. Most of our experience, our knowledge, and our thinking is organized as stories. The mental scope of story is magnified by projection - one story helps us make sense of another. The projection of one story onto another is parable, a basic cognitive principle that shows up everywhere, from simple actions like telling time to complex literary creations like Proust's À la recherche du temps perdu".

${ }^{4}$ Nesse sentido, a posição mais avançada é a de Gottfried Boehm, que analisa os mecanismos da criação (imagética) de sentido a partir do material da historia da arte. Cf. BOEHM (2007).
} 
Gellhaus, A. - Aspectos cognitivos da literatura

aplicabilidade do esquema no contexto da comunicação social e para a objetivação de atos de pensamento está limitada aos casos para os quais o esquema determina a moldura adequada. A psicologia cognitiva diferencia tais casos daqueles nos quais uma situação inesperada, surpreendente, exige uma nova estratégia. O que ocorre no nível do comportamento pessoal em situações supreendentes também acontece, necessariamente e com frequência, nas formas humanas de articulação que classificamos entre as artes: as artes podem ser consideradas como uma conquista altamente efetiva na apropriação cognitiva do mundo e na auto-organização da convivência humana, se não virmos nelas, em primeiro lugar, a produção de artefatos, mas o trabalho permanente de verificação de hábitos de percepção, articulação e pensamento. Acontecimentos históricos assemelham-se às "situações surpreendentes" da psicologia e exigem a substituição (a sobrescrição [Überschreibung]) de esquemas antigos.

Nesse ponto devem ser mencionados alguns aspectos que seriam dignos de uma consideração mais detalhada, e eu compreendo este esboço - mais que isso não será possível agora - como prolegômenos para uma investigação sistemática que ainda deverá ser escrita. ${ }^{5}$

Um experimento de reflexão: imaginemos que não houvesse as "belas-letras". O que faltaria? Para responder à pergunta, deveríamos diferenciar: o que faltaria aos que produzem literatura, aos escritores, e o que faltaria aos receptores, aos leitores? Comecemos pelos receptores: o que faltaria se não houvesse a Odisseia ou a Ilíada? Se não houvesse nem Édipo nem Antígona, nem Cassandra, nem Ifigênia, nem Pentesileia, nem Dom Quixote, nem o Doutor Fausto, nem Madame Bovary, nem Leopold Bloom, nem Ulrich, o homem sem qualidades, e nem Gregor Samsa, o inseto, nem Sam Spade, nem Oskar Matzerath tocando o tambor, nem, nem nem? O que faltaria à organização interior da consciência moderna, contemporânea, se faltassem não apenas os protagonistas dessa lista, mas também o seu contexto literário? Faltaria algo mais no apartamento da nossa consciência do que a decoração de quadros que podemos trocar nas paredes? É de se supor que a resposta não seja tão difícil, pois os nomes acima

\footnotetext{
${ }^{5}$ Um simpósio sobre o tema "Cognitive Functions of Literature and the Act of Writing", que será organizado em novembro de 2010 pelo grupo Brain-Concept-Writing (HumTec, RWTH Aachen Universtity) em cooperação com o Centre for Manuscripts Genetics (University of Antwerp), servirá como preparação de uma investigação sistemática.
} 
Gellhaus, A. - Aspectos cognitivos da literatura

pertencem - como modelos [Modelle $]^{\mathrm{iii}}$ do agir humano e da essência humana - de tal forma ao nosso aparato básico intelectual que nós na verdade não conseguimos prescindir deles, ao menos se tivermos crescido no âmbito cultural ocidental. Eles pertencem à formação geral, assim como o cânon das literaturas correspondentes. Mas o que se compreende, no nosso contexto, pelo conceito de "formação", que se tornou tão impopular?

Os nomes da lista acima funcionam como modelos [Modelle], como metonímias ou metáforas de situações de vida e de experiências de mundo. Metáforas - segundo a minha teoria - exercem no âmbito da língua a mesma função que as fórmulas possuem no âmbito da matemática: elas reduzem complexidade e são usadas como "macros" que nos permitem identificar e articular mais rapidamente as situações que percebemos. É interessante que às vezes as "macros" funcionam até mesmo quando uma metáfora é usada de forma errada (do ponto de vista filológico!). Tomemos como exemplo os troianos. Nós todos sabemos o que é um troiano no mundo da informática, ou seja, um vírus disfarçado - naturalmente, isso também é uma metáfora. Mas a utilização está errada do ponto de vista filológico, pois se refere ao truque dos gregos que, para conquistar Troia, utilizaram um cavalo de madeira como suposta oferenda. Na verdade, o que se chama de "troiano" na linguagem cotidiana da informática são portanto os gregos, mas mesmo assim todos nós entendemos o que isso quer dizer. Porém, as metáforas não surgem do nada na linguagem, elas precisam de um contexto, de um certo espaço livre. O lugar genuíno de criação da metáfora é a literatura - ou ao menos: um uso da linguagem especificamente literário, não o uso conceitual.

Observemos agora quem produz literatura: o que faltaria se não houvesse um medium no qual perceber, pensar, reconhecer, concluir, julgar e recordar não pudessem ser objetivados sem consequências imediatas? Se não possuíssemos o espaço e as objetivações do meio da literatura, deveríamos recomeçar sempre do início, não poderíamos pressupor nada como patrimônio comum do conhecimento de mundo, as lembranças seriam perdidas com o órgão do corpo que as produzia e a sociedade não teria nenhuma possibilidade de se planejar de forma mais inteligente, ou seja, mais

\footnotetext{
iii $\operatorname{Modelo}(s)$, em português, será a tradução constante para o termo Modell(e), utilizado pelo autor conforme a explicação que se segue no próprio texto. N. d. T.
} 
Gellhaus, A. - Aspectos cognitivos da literatura

diferenciada e experiente, do que uma sociedade anterior. Sem o drama Antígona a próxima geração viveria o mesmo conflito sangrento, a mesma aporia, pois ela não estaria em condições de pensar em um compromisso entre o direito estatal de Creonte e a lei natural de Antígona. Nesse sentido seria possível dizer que a literatura é um arquivo inesgotável de experiência humana de mundo, um gigantesco banco de dados de atos de pensamento objetivados, que tornam possível algo como desenvolvimento no sentido de um processo de permanente diferenciação e adaptação de regras sociais.

Ao lado da função de objetivação e "extraterritorialização" de atos mentais que é uma função geral da escrita e também poderia ser exercida pelas formas não literárias de texto - surgem outras funções, entre as quais serão mencionadas apenas as mais importantes.

Uma contribuição genuína da literatura consiste na capacidade de objetivar linguisticamente experiências não-proposicionais. ${ }^{6}$ A literatura moderna trabalha na articulação do antes não-articulável, trabalha com os meios linguísticos e formais para a representação das assim chamadas experiências-limite como também de experiências extralinguísticas (não-proposicionais). O âmbito de tais experiências não-proposicionais é muito amplo; ele abarca as impressões sensoriais imediatas e pré-linguísticas, como experiências de sons, cores, odores e impressões táteis, mas também experiências altamente complexas, marcadas emocionalmente, como traumas e recordações.

A linguagem também é o meio universal da comunicação e do pensamento, mas ela tem - como todo meio - limites performativos e sistemáticos. Dito de outra forma: a experiência humana e a articulação linguística sobrepõem-se, mas não são congruentes. Para autores considerados, pela recepção, representantes de uma época é possível dizer, de forma generalizante, que o motivo de sua atratividade consiste na capacidade de ter expandido a fronteira da experiência e da articulação. Talvez esteja aqui a possibilidade mais clara de diferenciação da literatura e da literatura trivial: a literatura trabalha no limite do não-proposicional e cria novas formas de articulação.

A literatura e as artes constroem modelos para a percepção de realidade e para a reconstrução de experiência. Kant nomeou esse procedimento da consciência humana,

\footnotetext{
${ }^{6}$ Sobre a definição filosófica do conceito, cf. SCHILDKNECHT (1999) e também SCHILDKNECHT 2004: 759-783.
} 
Gellhaus, A. - Aspectos cognitivos da literatura

com o qual a imaginação [Einbildungskraft] socorre o entendimento, de "síntese figurada" [figürliche Synthesis]. ${ }^{\text {iv }}$ Devido a tais processos de síntese, aos quais antecedem um processo de abstração e um processo de reconcretização, a consciência pode refletir o processo de sua aquisição do mundo em um objeto.

A literatura é, além disso, o espaço no qual modelos complexos de ação, modelos de convivência social ou de organização social e modelos da reflexão individual do ser-no-mundo [In-der-Welt-Sein] podem ser representados não apenas de forma rememorativa mas também de forma antecipatória.

Literatura e arte criam por fim espaços virtuais de percepção, cuja utilidade como modelo mostra-se apenas com o passar do tempo, na historia da recepção. Franz Kafka certamente não poderia pretender que um dia sua percepção do mundo se tornasse, sob o título "kafkiano", um tipo. Literatura e arte não nos colocam à disposição apenas possiblidades de expressão que podemos usar como um dicionário de retórica de fórmulas comprovadas, elas prefiguram como um esquema nossas impressões, ou seja, nossa percepção de situações complexas.

Se seguirmos essa argumentação, o cantinho dos brinquedos não parece ser mais a zona marginal - a não ser levada muito a sério - da consciência adulta, mas o laboratório de experimentos do intelecto. Que os mencionados aspectos cognitivos da literatura coincidam parcial e frequentemente com os aspectos cognitivos da linguagem está na natureza da questão. Para traçar uma linha de separação - mesmo que apenas tracejada - entre a função cognitiva da linguagem e a função cognitiva da literatura, é importante perguntar como surgem e através de quais fenômenos são provocadas, na história da linguagem, mudanças na utilização de metáforas e de modelos.

Eu gostaria, por isso, de esclarecer melhor a tese da função de modelo [Modellfunktion] com o exemplo da experiência do espaço. ${ }^{7}$ A literatura é, desde partida, intuitiva [anschaulich] e por isso se serve necessariamente das formas básicas da intuição [Anschauung]: espaço e tempo. Representações literárias são

\footnotetext{
iv Para a tradução dos termos e das citações de Kant, utilizou-se aqui a tradução portuguesa. Cf. KANT (2010). N. d. T.

${ }^{7}$ Essa relação foi apresentada de forma mais detalhada no meu livro GELLHAUS (2008).
} 
Gellhaus, A. - Aspectos cognitivos da literatura

fundamentalmente dispostas e ritmizadas no espaço. Com isso a literatura transporta e configura, ao mesmo tempo, o que se poderia chamar de experiência do espaço.

Pelo caminho empírico-experimental, na antropobiologia e na neurolinguística, chegou-se à convicção de que, com a gênese do homo sapien sapiens, existe uma relação estreita e provavelmente causal entre o desenvolvimento da motricidade e o desenvolvimento da linguagem humana. $O$ andar ereto e a experiência espacial possibilitada por ele a quem anda parecem ter impregnado o repertório gestual do homem que fala - os gestos seriam, do ponto de vista antropogenético, uma primeiríssima transformação, neurologicamente explicável, do pé para a mão.

Porém, esse fenômeno, reconstruído genealogicamente, não foi substituído por um mecanismo mais complexo ou mais inteligente em um estágio posterior da história da civilização, senão nem poderia ter sido reconstruído e, ao contrário, hoje pode ser comprovado em termos fisiológico-cerebrais a qualquer momento, através de experimentos. Aprendemos dos neurolinguistas que, ao falar, também estão ativas as partes do cérebro responsáveis pelo controle da motricidade da mão. (Cf. FEHRMANNJÄGER 2004: 311-341; FEHRMANN 2004: 118s; ANDERSON-DAMASIO-DAMASIO 1990: 749-766.)

A transposição da experiência do espaço e do movimento corporal para a configuração linguística de conteúdos de consciência pode ser documentada etimologicamente de várias formas, por exemplo, no âmbito linguístico indogermânico como relação histórico-linguística de "sentido" [Sinn], por um lado, e "caminho, andar, direção" [Weg, Gang, Richtung], por outro (Cf. GRIMM 1984: coluna 1103). Ernst CASSIRER ressaltou a relação evidente, demonstrável do ponto de vista linguísticohistórico, entre os pronomes pessoais e os demonstrativos de espaço, que já teriam sido apontados por Wilhelm von Humboldt:

Graças a essa inter-relação, também na linguagem o „caminho para o exterior“ torna-se, ao mesmo tempo, o „caminho para o interior“. É somente na medida em que a intuição externa adquire uma precisão crescente na linguagem, que a intuição interna pode realmente desenvolver-se: precisamente a configuração das palavras referentes ao espaço torna-se, para a linguagem, o meio de que ela 
Gellhaus, A. - Aspectos cognitivos da literatura

necessita para a designação do eu e para a sua delimitação em face de outros sujeitos. (CASSIRER 2001: 233) ${ }^{8}$

Diante dos muitos possíveis exemplos da cultura textual, não há dúvida de que seria possível desenvolver esse pensamento e também reencontrar uma organização gestual interessante, para o linguista, dos atos de fala no nível da escrita, como forma de organização da escrita teórica ou literária, portanto. Talvez sejam interessantes a forma como as experiências do espaço entram na linguagem cotidiana e sua relação com a escrita literária. Se, para além do debate sobre oralidade e literariedade, o ato da escrita for imaginado como processo mental, seria possível dizer ao menos uma coisa sobre ele, de acordo com os conhecimentos da pesquisa cerebral (ainda rudimentares com relação ao tema): ele é tudo menos linear.

$\mathrm{Na}$ ciência da genética do texto [Textgenetik], que só está se desenvolvendo aos poucos, observamos, em muitos escritores, na configuração de seus rascunhos portanto, nos primeiros estágios de fixação do texto - uma disposição gráfica do que será configurado. Isto é: antes que um texto se submeta às regularidades de sintaxe, gramática e direção, frequentemente os elementos mentais centrais são fixados em uma constelação gráfica bidimensional, ao menos - como gráfico -, o que uma pessoa que escreve conhece por experiência própria. $\mathrm{Na}$ medida em que esse gráfico ainda não possui uma direção de leitura clara, se deveria falar de um estado de simultaneidade dos elementos nele fixados. O processo de produção do texto consistiria então em transformar essa simultaneidade - que corresponderia ao estado mental de um sujeito, ou mais prudentemente: a suas objetivações linguísticas - em sucessão, em linearidade de um texto; aqui, poderíamos falar de sequencialização ou ritmificação. O que poderia se tornar problemático nesse processo é que existe, na consciência do sujeito, tanto do produtor quanto do receptor, um nexo entre sucessão e causalidade. Numerosos autores da modernidade parecem ter conhecido e refletido sobre essa problemática.

\footnotetext{
8 “Auch in der Sprache wird kraft dieser Wechselbeziehung der 'Weg nach außen' zugleich zum 'Weg nach innen'. An der wachsenden Bestimmtheit, die in ihr die äußere Anschauung gewinnt, gelangt auch die innere erst zur wahrhaften Entfaltung: gerade die Gestaltung der Raumworte wird für die Sprache zum Medium für die Beziehung des Ich und für seine Abgrenzung gegen andere Subjekte.” (CASSIRER 1982: $178 \mathrm{ss})$.
} 
$\mathrm{Na}$ tarefa de transformar um estado mental de tensão e de atenção na estrutura linear de um texto, o processo de escrita, como princípio ordenador ou esquema, servese com prazer da metáfora evidente da experiência de espaço corporal (conforme o modelo do "caminho de pensamento"v , da paisagem ou da cidade). Há que se perguntar, certamente, em quais limites esse procedimento esbarra devido a seus esquemas.

Já no funcionamento normal da atividade do entendimento [Verstandestätigkeit] - para formular com o termo de Kant - a ligação entre a variedade da intuição [Anschauung] e a exigência por unidades sintéticas, facilmente explicável a partir da infinita quantidade de detalhes, só é possível através da atividade mediadora de uma capacidade cognitiva, que o século XVIII chamou de imaginação [Einbildungskraft]. A imaginação concretiza, por exemplo, um conceito na medida em que ela o espacializa assim, mesmo uma das duas formas puras de intuição [reine Anschauungsformen], o tempo, só se torna visualizável através da imagem de sua extensão espacial, de um vetor. A espacialidade deveria ter um papel ainda mais importante quando a imaginação - como na poesia - precede a faculdade de compreensão do entendimento [Begriffsvermögen des Verstandes], ou seja, na medida em que ela cria uma imagem [Bild] para uma quantidade ou uma qualidade de intuições, imagem para a qual o entendimento ainda procura uma unidade sintético-conceitual, para a qual portanto ainda não existe um conceito. $O$ fenômeno da organização espacial de textos já inicia portanto com a metáfora espacial para a visualização de um conceito e termina nas estratégias narrativas de contos e romances, as quais se realizam em disposições espaciais: não se trata em nenhum nos dois casos de um instrumento de auxílio ingênuo ou limitado a um nível infantil da capacidade de articulação humana, o qual poderia ser imaginado como uma trilha mental de madeira no caminho rumo ao pensamento abstrato. Uma simples olhada na Crítica da razão pura (§ 24 da Dedução transcedental; B 154/155) poderia reforçar isso. Kant procura descrever o problema que surge através do abismo entre a unidade sintética da apercepção [Apperzeption], de um lado, e a variedade da intuição [Anschauung] de outro. Trata-se ali exatamente da ligação de entendimento e intuição. Essa ligação é estabelecida pela imaginação através de uma

\footnotetext{
${ }^{\vee} \mathrm{O}$ autor utiliza o termo Denkweg, em possível alusão aos escritos de Heidegger. N. d. T.
} 
Gellhaus, A. - Aspectos cognitivos da literatura

'ação transcendental' [transzendentale Handlung], que Kant também chama de "síntese figurada" [figürliche Synthesis] e que ele explica como se segue:

\begin{abstract}
Não podemos pensar uma linha sem a traçar em pensamento; nem pensar um círculo sem o descrever, nem obter a representação das três dimensões do espaço sem traçar três linhas perpendiculares entre si, a partir do mesmo ponto, nem mesmo representar o tempo sem que, ao traçar uma linha recta (que deverá ser a representação exterior figurada no tempo), atentemos no acto da síntese do diverso pelo qual determinamos sucessivamente o sentido interno e, assim, na sucessão desta determinação que nele tem lugar. O movimento, como acto do sujeito (não como determinação de um objecto) e, consequentemente, a síntese do diverso no espaço, quando deste abstrairmos para apenas considerar o acto pelo qual determinamos o sentido interno de acordo com a sua forma, é pois o que, antes de mais, produz o conceito de sucessão. $O$ entendimento não encontra no sentido interno tal ligação do diverso, por assim dizer, já feita: produ-la ao afectar esse sentido. (KANT 2010: 155s) ${ }^{9}$
\end{abstract}

Tal síntese figurada já está, portanto, em ação, quando se trata de fenômenos tão fundamentais quanto linha e círculo, vetor do tempo e sucessão.

As formas puras de intuição espaço e tempo como tais são tudo, menos visualizáveis [anschaulich]. Assim, para a síntese figurada, em contextos mais complexos, a imaginação necessita de uma reconcretização daquela intuição variada para dizê-lo agora em termos não-kantianos: das abstrações feitas da experiência corporal: espaço e tempo. A imaginação serve-se do espaço para a objetivação do tempo e, ao contrário, necessita do fator tempo para a visualização do espaço, na medida em que a intuição do espaço depende da possibilidade de medi-lo em passos ou em dias de marcha, de ele se mostrar como unidade figurada apenas ao sujeito que caminha ou, por exemplo, ao que voa.

\footnotetext{
9 "Wir können uns keine Linie denken, ohne sie in Gedanken zu ziehen, keinen Zirkel denken, ohne ihn zu beschreiben, die drei Abmessungen des Raums gar nicht vorstellen, ohne aus demselben Punkte drei Linien senkrecht auf eiinander zu setzen, und selbst die Zeit nicht ohne, indem wir im Ziehen einer geraden Linie (die die äußerlich figürliche Vorstellung der Zeit sein soll) bloß auf die Handlung der Synthesis des Mannigfaltigen, dadurch wir den inneren Sinn sukzessiv bestimmen, und dadurch auf die Sukzession dieser Bestimmung in demselben, Acht haben. Bewegung, als Handlung des Subjekts (nicht als Bestimmung eines Objekts), folglich die Synthesis des Mannigfaltigen im Raume, wenn wir vond iesem abstrahieren und bloß auf die Handlung Acht haben, dadurch wir den inneren Sinn seiner Form gemäß bestimmen, bringt so gar den Begriff der Sukzession zuerst hervor. Der Verstand findet also in diesem nicht etwa schon eine dergleichen Verbindung des Mannigfaltigen, sondern bringt sie hervor, indem er ihn affiziert." (KANT 1956: 150s).
} 
Gellhaus, A. - Aspectos cognitivos da literatura

Uma diferença mental decisiva já surge dos possíveis pontos a partir dos quais a experiência do espaço acontece: a perspectiva subjetiva do andarilho que não sabe o que o espera além do próximo pico de montanha comunica algo fundamentalmente diferente do olhar topográfico de cima. Essas experiências de espaço constroem o pressuposto para o termo mind-mapping, já estabelecido na neurologia.

"Sínteses figuradas" representam a integral de experiências espaço-temporais de forma modelar ou simbólica e entram na reserva geral de imagens das línguas, naturalmente também na linguagem imagética da pintura e do filme. Mas, visto que experiências espaço-temporais deslocam-se de forma significativa no decorrer da historia da cultura, isso também tem efeitos sobre as próprias sínteses.

Assim surge, e corresponde a um certo estágio de cultura e a seu modo de pensar, o conceito de paisagem ou de horizonte, na medida em que reencontramos nele as experiências de espaço e tempo, talvez a partir do século XVI tardio, como uma síntese estandartizada na literatura e na pintura. A paisagem - primeiramente uma síntese figurada no sujeito - torna-se um tipo, o tipo se torna um ideal e o ideal o padrão (script) de mudanças reais na configuração da paisagem, um pouco como Goethe tematiza e problematiza em Wahlverwandschaften [As afinidades eletivas]. Ampliando o conceito kantiano de síntese figurada, seria permitido lançar a tese de que aqui se encontra um esquema insistente, mas não estático, e tampouco uma ilustração arbitrária de nossa imaginação, mas um processo significativo em termos histórico-culturais, uma linguagem imagética do entendimento, que se serve até de diferentes formas de arte e cujo desenvolvimento de produtividade as historias da arte tradicionais reduziram a padrões de época: o tipo e suas metamorfoses são características marcantes para a constituição de um conceito de época; a epoché, a quebra histórica, sinaliza a necessidade de um novo tipo. Paisagem e cidade são esquemas, que porém não são totalmente fixos e, ao invés, só funcionam como esquemas quando mostram uma certa constância. A constância do esquema, da imagem de que o entendimento se serve para se apossar do variado, é ao mesmo tempo o inimigo do pensamento e da percepção do novo: intuibilidade [Anschaulichkeit] torna-se a cilada do pensamento e do conhecimento ao se tornar cliché. 
Gellhaus, A. - Aspectos cognitivos da literatura

$\mathrm{Na}$ terceira parte da sua Filosofia das formas simbólicas, Ernst CASSIRER descreve a criação da própria síntese figurada como um processo significativo do ponto de vista histórico-cultural; embora ele não utilize ali o termo kantiano, fala de Synopsis ou respectivamente do synhoran eis hen eidos [contemplação da unidade eidética, N. d. T.] platônico, o que se refere ao mesmo processo de consciência: para o autor, assim seria possível observar, em povos naturais, que eles possuiriam uma orientação espacial muito mais rigorosa e precisa em comparação a dos homens culturais; eles conheceriam, por exemplo, perfeitamente cada lugar particular e cada meandro de um rio, mas não estariam em condições de descrever esse percurso em um esquema espacial:

A transição da mera ação para o esquema, para o símbolo, para a representação significa, em cada caso, uma verdadeira "crise" da consciência do espaço, aliás, crise que não fica limitada ao círculo dessa consciência, mas que segue par a par com uma virada e uma transformação intelectual geral, com uma verdadeira "revolução no modo de pensar". (CASSIRER 2011: 260s) ${ }^{10}$

A experiência corporal do movimento no espaço é tão elementar para a coordenação espaço-temporal do sujeito, quanto fundamental como veículo no medium de um texto, de uma narrativa, também lá onde ela não é tematizada. Com a figura de uma pessoa que caminha - com a imagem do caminhar em uma paisagem ou em uma cidade -, o narrar cria para si uma possibilidade para concatenar os próprios passos de pensamento e argumentação e, respectivamente, os elementos individuais da narrativa, um padrão de ordenação espaço-temporal. Assim, Walter Benjamin pôde compreender o flaneur das passagens da metrópole como o tipo do homem moderno; o modelo do andarilho romântico esgotara sua tarefa após ter prefigurado, por várias décadas, na literatura, na música e na pintura, a experiência da natureza de um europeu esclarecido. Quando o planejador urbano Georges-Eugène Haussmann, o Barão Haussmann, inventou, com as passagens parisienses, o 'mundo interior do mundo exterior', foi preciso encontrar um novo tipo do movimento no espaço. O flaneur substituiu o andarilho. Qual tipo seria adequado à nossa experiência atual de espaço-tempo?

\footnotetext{
10 “Der Übergang von der bloßen Aktion zum Schema, zum Symbol, zur Darstellung bedeutet in jedem Fall eine echte 'Krisis' des Raumbewußtseins, und zwar eine solche, die nicht auf den Umkreis dieses Bewußtsein beschränkt bleibt, sondern die mit einer allgemeinen geistigen Wendung und Wandlung, mit einer eigentlichen "Revolution der Denkart" Hand in Hand geht." (Cf. CASSIRER 1985: 167).
} 
Gellhaus, A. - Aspectos cognitivos da literatura

O presente esboço limita-se à literatura; para descrever o quarto dos brinquedos do intelecto e fazer o seu inventário, evidentemente seria preciso acrescentar os modelos que as artes visuais e a música colocam à nossa disposição.

Se, no seu significado e na sua função cognitiva, essas formas básicas podem ser separadas hoje das mídias eletrônicas e do cinema, é de se duvidar. Mas embora as mídias técnicas sejam muito complexas e exijam do nosso cérebro uma competência de processamento de informação sempre maior, continuam a ser, enfim, variantes dos sempre mesmos elementos: imagem, texto, som. O grau de sua aceleração não prova que teria surgido algo novo, mas apenas o quanto a sua recepção se apoia em modelos. O estudo da produção de imagem, texto e som é, aliás, um programa de desaceleração que pode nos ajudar a compreender por que e como os modelos surgem.

\section{Referências bibliográficas}

Anderson, Steven W./DAMASIO, Antonio R./DAMASIO, Hanna. Troubled Letters but not Numbers. Domain Specific Cognitiv Impairments Following Focal Damage in Frontal Cortex. Brain 113 (1990), p. 749-766.

BoeHM, Gottfried. Wie Bilder Sinn erzeugen. Die Macht des Zeigens. Berlin: Berlin University Press 2007.

CASSIRER, Ernst. Philosophie der symbolischen Formen. Dritter Teil. Phänomenologie der Erkenntnis. Darmstadt, 1982.

CASSIRER, Ernst. Philosophie der symbolischen Formen. Erster Teil. Die Sprache. Darmstadt, 1985.

. Filosofia das formas simbólicas. I - A linguagem. [Trad. Marion Fleischer]. São Paulo: Martins Fontes 2001

. Filosofia das formas simbólicas. III - Fenomenologia do conhecimento. [Trad. Eurides A. de Souza; Ver. Flávio B. Wiebeneichler] São Paulo: Martins 2011 [Terceira parte]

ELSNER, Norbert/ FRICK, Werner (Hg). Scientia poetica. Literatur und Naturwissenschaft. Göttingen: de Gryter 2004.

FEHRMANN, Gisela/ JÄGER, Ludwig. Sprachbewegung und Raumerinnerung. Zur topographischen Medialität der Gebärdensprachen. In: LECHTERMANN, C./ MORSCH, C. (Hg.). Kunst der Bewegung. Kinästetische Wahrnehmung und Probehandeln in virtuellen Welten, Bern 2004. p. 311-341.

FEHRMANN, Gisela.Verzeichnung des Wissens. Überlegungen zu einer neurosemiologischen Theorie der sprachgeleiteten Konzeptgenese. München: Fink, 2004.

GellHaus, Axel. Schreibengehen. Literatur und Fotographie en passant. Köln, Wien: Böhlau, 2008. 
Gellhaus, A. - Aspectos cognitivos da literatura

KANT, Immanuel. Werke III. Kritik der reinen Vernunft I, hrsg. v. Wilhelm WEISCHEDEL. Wiesbaden 1956 [= 224 : Von der Anwendung der Kategorien auf Gegenstände der Sinne überhaupt].

. Crítica da razão pura. Trad. Manuela Pinto dos Santos e Alexandre Fradique Morujão. Lisboa: Calouste Gulbekian 2010. [7ª. edição]

SCHILDKNECHT, Christiane. Ausdrucksgrenzen: Theorien nicht-propositionaler Wissensformen. In: Grenzen und Grenzüberschreitung. XIX Deutscher Kongreß für Philosophie. Hrsg. v. Wilhelm HoGREBE inVerbingung mit Joachim BROMAND. Berlin 2004. S. 759-783.

StOCKWELl, Peter. Cognitive Poetics. An Introduction. London: Routledge, 2002.

TURNER, Mark. The Literary Mind. The Origins of Thought and Language. Oxford: Oxford UP, 1997.

Tradução: Juliana P. Perez

Tradução aprovada em 11/07/2012 